\title{
CINDERELA, IGREJA E INFÂNCIA: produção de masculinidade e feminilidade numa escola rural
}

\author{
Graziele Corrêa Amorim ${ }^{1}$ \\ Rúbria de Cássia Magalhães e Silva² \\ Heloísa Raimunda Herneck ${ }^{3}$
}

\begin{abstract}
Resumo: Como um projeto de "Cinema e Educação", uma narrativa cinematográfica "A Cinderela (1950)" capturada pelos estúdios da Disney e os dogmas de uma igreja Evangélica poderiam se encontrar? Nos cotidianos de uma sala de aula. Tais encontros foram produzidos numa escola localizada numa área rural da Zona da Mata mineira e aqui caligrafamos as redes que atravessaram a produção do tornar-se menino e menina naquele espaço. Nesse sentido, mergulhamos nos fluxos que nutrem a produção de estar criança na escola. E para potencializar a reflexão, utilizamos as narrativas e os estudos nos/dos/com os cotidianos para a composição da cena tramada. Consideramos que os papéis masculinos e femininos são invenções que atravessam todo um sistema social, religioso e econômico e que a escola é um espaço potente para pensarmos nas multiplicidades de existências. Como também, de escapes as categorizações nas produções de vidas.
\end{abstract}

Palavras-chave: Cotidiano Escolar; Infância; Diferença.

\section{CINDERELLA, THE CHURCH AND CHILDHOOD: the production of masculinity and femininity in a rural school}

\begin{abstract}
How could a project of "Cinema and Education", a cinematographic narrative "Cinderella (1950)" captured by the Walt Disney Studios and an evangelical church's dogmas meet? In the routine of a classroom. Such encounters were produced in a school in a rural area of Minas Gerais' Zona da Mata and where we tied up the nets that crossed the process of becoming a boy or a girl in such space. In that sense, we dove into the waves that nurture the act of being a child on school. And in order to empower reflection, we made use of narratives and studies of the proposed scene's composition. We consider the masculine and feminine roles interventions that cross the entirety of a social, religious and economic system and the school is a powerful space in which we're able to think in the multiplicities of one's existence. As well as escape from the categorizations in the production of lives.
\end{abstract}

Keywords: School routine, Childhood, Difference.

\section{Introdução}

Movimentarmo-nos, pois, junto ao cotidiano escolar força-nos a um agenciamento com mais dúvidas que certezas. Isso porque, o mesmo compõe-se em meio a uma multiplicidade de cores, afetos, saberes, desejos, medos, alegrias, tristezas, sonhos, enfim, de praticantes que dialogam, partilham e se estranham ao mesmo tempo. Diálogos e estranhamentos esses que extrapolam planejamentos pré-definidos, saberes únicos e verdadeiros, controles, normatizações, regras, imposições, punições de corpos

\footnotetext{
${ }^{1}$ Pedagoga e Mestre em Educação pela Universidade Federal de Viçosa. Professora Concursada dos anos iniciais do Ensino Fundamental, no estado de Minas Gerais.

${ }^{2}$ Graduada em Pedagogia pela UFV - Universidade Federal de Viçosa. Especialista em Inspeção Escolar e Psicopedagogia Clínica e Institucional. Mestranda em Educação pela UFV.

${ }^{3}$ Graduada em Pedagogia pela Universidade Federal de Viçosa. Atualmente professora adjunta no Departamento de Educação. Doutorado e Mestrado em Educação na Universidade Federal de São Carlos. Pós-doutorado na Universidade Federal do Espírito Santo, com pesquisa desenvolvida em Coimbra/Portugal na área de Formação Continuada de professores e sexualidade.
} 
que fogem aos padrões desejados... Passar, assim, a habitar tal cotidiano requer coragem, pois "pequenos lampejos" (LOPEZ, 2017) inesperadamente podem atravessar os protagonistas das escolas.

Nesse sentido, estes escritos emergiram a partir do encontro de uma das atividades de um projeto "Cinema e Educação" desenvolvido em uma escola rural, o filme Cinderela $(1950)^{4}$ produzido pelos estúdios da Disney ${ }^{5}$ e a escuta de um diálogo entre crianças do Ensino Fundamental I. Enoveladas a essa trindade narramos uma cena que ocorreu entre crianças pertencentes a famílias evangélicas, abrindo-nos a acompanhar os fios das tramas que atravessam os discursos anunciados no sentido de caligrafar a produção da feminilidade e da masculinidade que as mesmas inventam e engendram no cotidiano escolar.

Tecemos, assim, movimentos juntas aos afetos "experienciados" (LARROSA, $2002^{6}$ ) por crianças no cotidiano escolar, a partir da exibição de uma narrativa cinematográfica em que a princesa Cinderela é a personagem principal. Torna-se relevante o questionamento: quem é Cinderela? De canto doce, formoso e melancólico, com uma força capaz de transportar um elefante, a ave Fênix, também é conhecida por renascer das suas próprias cinzas. Ela, personagem de um conto de fada, apelidada de Cinderela, teve adicionado ao seu nome o prefixo cinder. Tal termo faz referência a aparência da personagem que a fisionomia estava marcada pelos borralhos das cinzas das suas obrigações domésticas.

Tramadas e, igualmente, marcadas pelos borralhos das cinzas de uma religião e de um cotidiano escolar, onde ambos em muitos momentos insistem em produzir o tornar-se meninas mulheres e meninos homens, as crianças inventam outros mecanismos de existências que podem extrapolar o desejado no contexto em que se fazem imersas. Reinvenções agenciadas a caminhos inesperados e singulares, configurando-se "[...] muito mais como espaços de des-caminhos, incertos, tênues, sinuosos, que fogem aos lugares seguros de verdades e certezas, embora os eventos proporcionem certa compreensão aguda dos sentidos em torno dos quais se dão" (LEITE, 2011, p. 71).

\footnotetext{
${ }^{4} \mathrm{O}$ filme pode ser encontrado no link a seguir: https://www.youtube.com/watch?v=oIaqF_ISvQw.

5 A Walt Disney Animation Studios, anteriormente conhecida como Walt Disney Feature Animation e Disney Brothers Cartoon Studio, é conhecido como um estúdio de animação americano sediado em Burbank que produz longas-metragens e curtas-metragens.

${ }^{6}$ Experienciar agencia-se ao conceito de experiência, sendo esta o "[...] que nos passa, o que nos acontece, o que nos toca. Não o que se passa, não o que acontece, ou o que toca. A cada dia se passam muitas coisas, porém, ao mesmo tempo, quase nada nos acontece” (LARROSA, 2002, p. 22).
} 
Para potencializar a tessitura dessa rede, como recurso, mergulhamos nos estudos em/com os cotidianos escolares e das narrativas, uma vez que acreditamos serem valiosas fontes de construções de realidades possíveis. Dessa forma, é importante salientarmos que o cotidiano defendido nestas linhas extrapola a concepção de repetição monótona e banal. Simonini, Botelho e Amorim (2014, p. 217) compreendem o cotidiano como sendo "um verbo e não um substantivo". Nesse viés, gramaticalmente, a classe dos substantivos dá nome a todos os seres vivos e a todas as coisas, porém, sempre está submetida a variações conforme o gênero (feminino e masculino), o número (singular e plural) e o grau (aumentativo e diminutivo). Então, o substantivo cotidiano subordina-se a essas variações externas. Por outro lado, a classe de palavras dos verbos indica ação e/ou movimento, que ganham outras entonações na medida das composições em que o contexto linguístico estabelece. Acreditamos e mergulhamos no/com o cotidiano escolar do modo proposto pelos referidos autores, o compreendendo como uma ação em movimento e não como uma substância estabilizada e territorializada em um lugar específico.

Abrimo-nos a reflexões junto a um cotidiano escolar mutável, inventivo e que possibilita "deslocamentos de pensamentos" (DELEUZE, 1996). Dessa forma, sensibilizamo-nos a produzir uma conexão entre Cinderela - personagem conhecida de um conto de fada -, as crianças e o cotidiano escolar que as mesmas habitam, dialogando e afetando-nos com as produções de viver tramadas nessa relação. Portanto, muitas questões se fazem importantes, sendo uma delas: como os contos de fadas podem se agenciar as nossas existências?

\section{Contos de fadas: dos usos da escrita aos estúdios de animação}

Os contos de fadas, concebidos como um conjunto de histórias que narram problemas e superações de determinados personagens, podem ser tomados também como instrumentos de aprendizagens. Seja para os conteúdos escolares ou mesmo para arquitetar as existências das pessoas em múltiplos outros espaços cotidianos. Isso porque, como nos ajuda Huston (2010) eles são potentes produtores de sentidos. Conforme a historiadora, “[...] o universo como tal não tem Sentido. Ele é silêncio. Ninguém pôs Sentido no mundo, ninguém além de nós. O Sentido depende do humano, e o humano depende do Sentido" (HUSTON, 2010, p. 18). Desse modo, compreendemos que junto ao conto de fada muitos sujeitos se fortalecem e passam 
também a acreditar na construção harmônica de seus viveres.

Partindo das produções de sentidos, seja da distração de uma contação de história aos estudos da estrutura literária e linguística desse gênero, podendo ser para ensinar ou encantar, essa construção narrativa conhecida como conto de fada provoca em muitos dos seus leitores e ouvintes um significado para resolução dos problemas encontrados. Desse modo:

Essa é exatamente a mensagem que os contos de fadas transmitem à criança de forma variada: que uma luta contra dificuldades graves na vida é inevitável, é parte intrínseca da existência humana - mas que, se a pessoa não se intimida e se defronta resolutamente com as provocações inesperadas e muitas vezes injustas, dominará todos os obstáculos e ao fim emergirá vitoriosa (BETHELHEIM, 2007, p.15).

Potencializando, pois, a discussão Bethelheim (2007), Bastos (2015) e Breder (2013) destacam que as histórias denominadas de contos de fadas podem influenciar no modo como, em especial, as crianças lidam com os problemas cotidianos que as atravessam. Isso ocorre, pois, podem encontrar nessas narrativas, exemplos, que as encorajam a pensar, a arriscar e a solucionar possíveis confrontos. Afinal, do mesmo modo que os personagens nas tramas finalizam as histórias superando conflitos inusitados as crianças também se sentem capazes.

Caminhar em busca de uma origem para esses contos, não é uma tarefa tranquila e muito menos linear. Contudo, encontramos que o conto de fada agencia a história oral. Dessa forma, os contos orais ganharam novas conotações com o passar do tempo, do espaço e das necessidades existenciais que emergiram em diferentes épocas. Tradicionalmente, considera-se que foram três editores desses contos, sendo os irmãos Jacob e Wilhen Grimm ${ }^{7}$ (1812) e Perrault ${ }^{8}$ (1717). Considerados os primeiros a escreverem e usarem da imprensa para veiculação dessas histórias, esse fato deve-se a um novo contorno que a infância vinha ganhando com a emergência da burguesia.

Santos (2011) descreve que Perrault adaptou as narrativas já existentes para que fossem úteis a corte francesa do rei Luís XIV. Reformulou, então, as histórias que ouvia em busca de ofuscar temáticas que pudessem ser atravessadas por discussões sobre

\footnotetext{
${ }^{7}$ Os Irmãos Grimm se formaram em Direito na Universidade de Kassel, decidiram trabalhar com história e Filologia - sendo a segunda considerada o estudo cientifico de textos e do desenvolvimento de uma língua. Assim, para Santos (2011) os irmãos Grimm tiveram grande interesse em estudar a própria língua alemã e, igualmente, as histórias que as pessoas contavam no local que habitavam.

${ }^{8}$ Charles Perrault (Paris, 1628 - 1703), formou-se em Direito. Foi um escritor e poeta francês do século XVII. Estabeleceu as bases para um novo gênero literário, o conto de fadas, além de ter sido o primeiro a dar acabamento literário a esse tipo de literatura, o que lhe conferiu o título de "Pai da Literatura Infantil".
} 
violência e sexualidade, acrescentando lições de morais que contribuíssem na difusão de modos de viver julgados como corretos pela nobreza. O francês também se preocupou em produzir uma escrita de fácil compreensão para que pudesse ser aceita, compreendida e moralizasse com mais agilidade a população.

Muitas dessas histórias que compuseram uma coletânea arquitetada por Perrault, conhecidas nos dias de hoje, possibilitou um reconhecimento a imagem do mesmo e, inclusive, propiciou que tais narrativas fossem consideradas como contos de fadas. No entanto, para Coelho (2000, p. 90):

[...] vulgarmente, tais estórias circulam na França (e daí para os demais países) como 'contos de fadas', rótulo que os franceses usam até hoje para indicar 'contos maravilhosos' em geral. Nessa coletânea, a metade não apresenta fadas. São apenas 'contos maravilhosos', por existirem em um espaço 'maravilhoso', isto é, fora da realidade concreta.

A partir de então, considera-se que aos poucos as produções dos contos de fadas ganharam outras cores, formas, fantasias e intencionalidades, influenciando a sua (re)invenção junto a um emaranhado de outras temáticas. Desse modo, compreende-se que essas histórias se movimentam em tantas outras configurações que buscam reforçar e/ou reproduzir características julgadas como ideais a serem incorporadas aos diferentes contextos vivenciados.

Assumimos, assim, junto a esses escritos que os contos de fadas podem ser considerados dispositivos que enunciam maneiras de produzir a existência. Nesse sentido, capturados pela indústria da mídia, compreende-se que um dos estúdios que trabalha há tempos em busca de padronizar determinados enredos e imagens é a Disney.

Conforme Santos (2011), essa veiculação de filmes baseados em contos de fadas iniciou com a estreia de Branca de Neve e os sete anões no ano de 1938. A partir de então, a Disney, junto aos seus estúdios, aprimorou a linha de princesas, produzindo uma franquia mundial de variados produtos e filmes baseado nas personagens de contos de fadas clássicos, tais como: Bela ${ }^{9}$, Cinderela ${ }^{10}$, Aurora ${ }^{11}$, Ariel ${ }^{12}$, entre tantas outras adoradas por crianças.

Breder (2013), em um estudo sobre a possível influência desse estúdio - Disney - no imaginário dos seus seguidores, elencou uma série de pesquisadores que se

\footnotetext{
${ }^{9}$ Personagem do conto "A Bela e a Fera".

${ }^{10}$ Personagem do conto "Cinderela".

${ }^{11}$ Personagem do conto "A Bela Adormecida".

${ }^{12}$ Personagem do conto "A Pequena Sereia".
} 
dedicam a refletir sobre a deterioração da "imaginação e faria com que o indivíduo passasse a se abastecer apenas de imagens feitas" (BREDER, 2013, p. 24). Mergulhadas nesse posicionamento, nos questionamos, para além dessas imagens prédefinidas, como esses enredos influenciam a produção de meninas e meninos? Isso porque, agenciadas aos autores apresentados nesses escritos, entendemos que os contos de fadas podem encorajar e fortificar sujeitos em seu viver cotidiano, como também anunciam, definem e reforçam possíveis espaços a serem ocupados pelas mulheres e homens em distintas existências.

Isto posto, navegamo-nos em uma discussão e reflexão junto aos afetos das crianças de uma escola rural, a exibição cinematográfica do filme "Cinderela de 1950" e o projeto denominado de "Cinema e Educação". Abrindo-nos a pensar e, igualmente, a acompanhar distintas produções dos tornarem-se meninas mulheres e meninos homens a partir da relação acima referenciada. Narramos, portanto, cenas que nos convocam a aprender com as crianças, uma vez que as mesmas arquitetam “[...] um mundo em reticências, um mundo pontilhado de possibilidades pelo ritmo cortado, sem sentido fixo, sem sentido dado, sem sentido previsto, sem sentido" (LEITE, 2011, p. 116), metamorfoseando constantemente as suas e as existências de todos aqueles que as rodeiam.

\section{Luz, câmera, ação: cena de um cotidiano escolar}

A escola pode ser produzida como um espaço cinematográfico. Isso porque, lá temos: direção, roteiros, atrizes e atores. Cenários e figurinos. Enquadramentos e montagens. Propagandas, protagonistas e espectadores. Repetimos cenas exaustivamente. E a visita do imprevisto e do inédito atravessa a reincidência das práticas cotidianas. Práticas cotidianas agenciadas a "[...] pensamentos sem sentidos, rotineiros e ameaçados, [onde] há sempre a ameaça de um corpo invadindo o outro" (LEITE, 2011, p. 227). Ou ainda como ponderou Deleuze (1996), "não sabemos sequer o que um corpo pode".

Sendo assim, a tessitura e a leitura desses escritos não devem ser compreendidas como verdade absoluta, mas como uma produção cotidiana que pode enovelar-se a outros sentidos e ritmos a depender das redes de saberes acionadas ao pensar de cada sujeito. Aliando-nos, então, às imprevisibilidades dos contatos entre múltiplos corpos, apresentamos cenas de um cotidiano escolar que atravessam as nossas vivências e esses escritos. 
Desse modo, localizada numa área rural do interior da Zona da Mata do Estado de Minas Gerais o cenário dessa trama é acolhido pelas montanhas aradas, climatizada pelo descompasso das brisas serranas e distante do progresso do asfalto. Ali, como em qualquer outro pedaço do mundo, pulsavam uma multiplicidade de ritmos de vida.

Tramada pela sétima arte desde o tempo da graduação em Pedagogia na Universidade Federal de Viçosa (UFV), uma de nós viveu a experiência da direção de um projeto sobre o cinema e educação que envolveu todos os praticantes da escola que lecionava. Tal projeto, denominado de "Cinema e Educação", tinha como objetivo exibir, quinzenalmente, filmes infantis diversos. Logo após a exibição era propiciado conversações, entre as crianças dos anos iniciais do ensino fundamental I e professores, no intuito de expressarem os afetos que emergiram a partir da película apresentada.

Os desdobramentos daquele exercício toparam com um caminho que dividiu as expectativas das crianças e também da professora responsável pelo projeto. Tal rachadura ocorreu ao final do projeto assim que a docente sugeriu a construção de um Oscar na escola. Assim, apropriando-se do nome do maior evento hollywoodiano ${ }^{13}$ de premiação cinematográfica, foi proposto que as crianças votassem nos filmes que mais as afetaram.

Contudo, durante a votação um dos alunos, nomeado neste texto de Adílio $^{14}$, questionou: Tia, por que o filme Cinderela não entrou na votação do Oscar no nosso projeto sobre Cinema e Educação? Assustada com tal questionamento, a professora confessou que, com uma tonalidade ríspida, o respondeu que o filme Cinderela não fazia parte do projeto, afinal foi exibido por outra docente em um contexto distinto. Junto àquela resposta, a professora responsável pelo projeto considerou que o filme Cinderela deveria ser discutido apenas com a educadora que o exibiu.

Diante da pergunta de Adílio e enovelada à tessitura deste trabalho, reconheceuse a dificuldade de a professora lidar com os filmes considerados contos de fada, pois, essa acredita que tais produtos reforçam estereótipos, configurando um padrão de beleza e comportamento na educação de meninas e meninos. Dificuldade essa que atravessa tantas outras falas, gestos e emoções imprevisíveis que podem emergir na relação entre professoras, crianças e os filmes.

13 Oscar é o nome dado a uma cerimônia de premiação da Academia de Artes e Ciências Cinematográficas. Foi um evento fundado em Los Angeles (Califórnia) em 1927, que presenteia anualmente os profissionais da indústria cinematográfica com o prêmio Oscar, em reconhecimento à excelência do trabalho e conquistas na arte da produção cinematográfica.

${ }^{14}$ Para preservar a identidade, criamos um nome fictício. 
Atenta a sua dificuldade em reproduzir filmes sobre contos de fadas, a professora compreendeu as razões da sua colega de trabalho ao exibi-los: essa o fez, pois tal narrativa expressa um estereótipo de formação para comportamentos de meninos e meninas que se aliam a sua expressão religiosa que tem caráter protestante evangélica ${ }^{15}$. Expressão religiosa essa que também era seguida por muitas famílias das crianças que compunham aquele cotidiano escolar. Talvez por isso, os contos de fadas estivessem nas predileções cotidianas de uma grande parte dos alunos.

Percebendo, pois, a rispidez da professora ao lidar com o questionamento feito pelo colega, uma aluna, Gabriela ${ }^{16}$ replicou "nada a ver você gostar de filme da Cinderela, são filmes para mulheres. Lá na igreja mesmo você disse que não iria juntar com as meninas para brincar de princesas... Se esqueceu que ela [Cinderela] também é uma princesa. Não estou entendendo mais nada!'. Diante dos dizeres da menina, Adílio calou-se e sem uma resposta para o seu questionamento, anunciou que votaria em outro filme que fizesse parte do projeto e, talvez, que se aproximasse do socialmente classificado como pertencente ao mundo masculino.

A fala de Gabriela propõe-nos duas percepções: a primeira remete a um questionamento por parte da colega devido às preferências do menino por objetos, leituras e atitudes vinculadas socialmente a comportamentos femininos. A segunda, no modo como o espaço religioso frequentado pelas crianças junto com as suas famílias e a escola são fronteiras de composições. Foucault (2017) nos aponta que nossas predileções, gostos e/ou atitudes agenciam-se aos contextos em que nos fazemos imersos, sejam eles de cunhos religiosos, sociais, raciais, orientados por escolhas sexuais, pelas classes sociais, entre tantos outros aspectos que insistem em nos atravessar.

Consideramos, assim, que Adílio possa ter negado a participação na brincadeira de princesas por pertencer a uma família que se aporta nos dogmas das igrejas evangélicas. Nesse sentido, o lúdico apresentado diante dos pais do menino poderia ser analisado como uma brincadeira a ser praticada somente por meninas e naquele espaço, junto com seus pais Adílio pode ter se sentido retraído a participar da brincadeira. Isso

\footnotetext{
${ }^{15}$ Professora seguidora fiel da religião evangélica, a mesma exibiu muitos outros filmes de princesas no cotidiano escolar para todas as crianças. Contudo, distinto da proposta do projeto "Cinema e Educação", a educadora não abria espaço para que meninas e meninos pudessem dialogar sobre os possíveis afetos que poderiam emergir na relação espectador e narrativa cinematográfica. Desse modo, era a mesma quem narrava as percepções e como dizia, os ensinamentos, os valores e as cenas principais das narrativas cinematográficas para todas as crianças.

${ }^{16}$ Para preservar a identidade, criamos um nome fictício.
} 
porque, conforme outras falas acompanhadas por crianças, naquele templo frequentado não são permitidas certas ludicidades por parte dos meninos, como, por exemplo, "meninos brincarem com personagens compreendidas como femininas" (Gabriela). Enquanto na escola, além de assistir junto com as meninas filmes considerados conto de fada, o aluno também se sentiu confortável em exibir seus gostos, afetos e preferências por filmes de princesas. Adílio extrapola seus afetos junto com a narrativa cinematográfica, uma vez que “[...] não fala de lugares, se porventura falar, talvez possa falar de percursos, caminhadas, trilhas" (LEITE, 2011, p. 25), com outras formas de produzir sensações com o categorizado socialmente como feminino e masculino.

A trama se estendeu com a entrada de Fernanda ${ }^{17}$ que, entre suspiros, desabafou: “Ah, quero ser como Cinderela". Após esses dizeres, com um sorriso Gabriela a confortou: "Mas você já é! É bonita, magra, tem cabelo bom [liso] e logo... logo encontrará um príncipe, mas um de carro". Enquanto as duas meninas conversavam, Adílio as ouvia silenciosamente. A nosso ver, era como se tal conversa alimentasse também as incertezas que permaneciam entre o aluno e o questionamento que ele havia feito para a professora.

Acreditamos que Adílio encontrou algo no filme Cinderela (1950) que o afetou de algum modo. Isso porque, para Santos (2011), os contos de fadas, concebidos como um conjunto de histórias que narram problemas e superações de determinados personagens, podem ser tomados como instrumentos de aprendizagens. Seja para os conteúdos escolares ou mesmo para arquitetar as existências das pessoas em múltiplos outros espaços cotidianos. Destacamos, assim, como esse gênero é importante para construção da criança e de como essas narrativas produzem sentido. $\mathrm{O}$ que nos indica a necessidade de construir fabulações que contemplem as multiplicidades de existências, não restringindo um mesmo conteúdo a seriadas imitações.

Retornando à distribuição das cédulas para eleição do Oscar, a professora acompanhou o restante da conversa entre as alunas Fernanda e Gabriela. Essa última afirmou que "em casa já sei até cozinhar e lavar louças. Às vezes é até chato, pois ajudo muito minha mãe. Mas fazer o quê, né! Minha mãe disse que esse é o papel de mulher". A seguir, Fernanda demonstrou a dificuldade de tornar-se uma princesa " $e u$ não poderia ser a Cinderela, meu cabelo é ruim. E outra, não sou muito chegada nesses vestidos que ela [Cinderela] usa não. Minhas amigas falam que sou estabanada.

\footnotetext{
${ }^{17}$ Para preservar a identidade, criamos um nome fictício.
} 


\section{E sou mesmo. Nada que eu faço tem perfeição".}

Nesse cenário encontramos duas meninas diante da espera da aprovação do outro. Uma representa a virtude da beleza física e a outra o prestígio pelo martírio. Ambas indicam que para seduzir o outro é preciso atraí-lo, aludindo-o a investir no culto do belo que produzem. Fernanda e Gabriela querem ser resgatadas por um outro, seja essa pela beleza da sua aparência e qualidades, ou aquela pelo esforço de atingir uma perfeição. Desejos esses também cultivados em muitas histórias consideradas como contos de fadas, como, por exemplo, a Cinderela do ano de 1950.

As falas das meninas também nos inquietam quanto aos afetos que construímos entre as gerações. Suas mães, irmãs mais velhas e avós, são produtoras e condutoras de alianças sobre os papéis femininos e masculinos aceitos ou não. Muitas vezes enquanto esperam, como no caso de Cinderela, renunciam a uma liberdade, se comprometem em atividades que facilitam ou promovem um futuro mais auspicioso. Gabriela expressa uma beleza de princesa com comportamento que tudo indica que um príncipe pode vir ao seu resgate, principalmente quando a mãe a coloca para aprender as atividades do lar.

Não queremos dizer que não seja importante as crianças colaborarem nos trabalhos domésticos, mas atentando à importância de também questionarmos as narrativas que sustentam o envolvimento ou não delas nos serviços da casa. Será que Adílio compartilha das mesmas colaborações com as demandas da casa que habita?

O silêncio do menino na brincadeira na igreja, conforme mencionado pelas companheiras de escola, pode representar a dificuldade daquelas crianças em ocupar espaços subjetivados como pertencentes às mulheres. E talvez o espaço que ele encontrou para conversar sobre essas representações, que seria com a professora que organizou o projeto de cinema e educação na escola, foi silenciado pelo não envolvimento dessa docente com o filme que sua colega de docência optou por apresentar aos seus alunos.

Consideramos, portanto, que Cinderela afetou Adílio de tal modo que ele gostaria de ver essa película entre os filmes do Oscar da escola, mas as redes de mulheres que o envolveu na escola, de algum modo, silenciaram seu desejo frente às verdades e os sentidos que essa narrativa o provocou. Entrelaçadas as considerações da autora Huston (2010), acreditamos que há tempos os contos de fadas, mais especificamente o filme Cinderela de 1950, habitam diferentes espaços escolares. Isso porque reforçam maneiras de existir concebidas como corretas e ideais a serem seguidas por meninas mulheres e meninos homens em diferentes instâncias. Vale ainda 
ressaltar que, atualmente, foram produzidas múltiplas outras narrativas cinematográficas que propõem um novo perfil para as princesas, citamos, como exemplo, Deu a Louca na Cinderela ${ }^{18}$. Contudo, no cotidiano escolar narrado e em tantos outros espaços de ensino insistem em fabricar conversações com os contos de fadas clássicos (antigos) ${ }^{19}$.

\section{Vivemos fabulando por toda a nossa existência...}

Bruno Latour (2002) contesta a crença dessa perfeição dizendo que a busca de um universal é fe(i)tiche. O fetiche é algo construído, é encantado, como um feitiço. Crer em algo é falar que a sua fantasia é a realidade. $\mathrm{O}$ autor exemplifica apresentando como o europeu desfaz dos deuses e amuletos das culturas que encontraram e não enxergam que o deus e as imagens dos santos em que acreditam, representam códigos que desenham uma determinada realidade, ambos produzem ídolos. Não existe antifetiches, uma verdade que se sobrepõe a outra, uma realidade mais certa e adequada. Latour (2002) reforça que não devemos ficar no discurso se é verdade ou não, mas sim nos efeitos que o meu fetiche produz. Tal efeito é o que costumamos chamar de realidade, essa é fabricada pelos nossos fetiches. A novidade deste autor é que a realidade não é algo externo, é construída, produzida, sempre em vias de conectar-se a outros nuances...

Em uma conexão com Huston (2010), compreendemos que nós, seres humanos, existimos através das narrativas que fabulamos. Fabulações essas que se referem às narrativas que nos contam e que contamos a nosso respeito, produzindo maneiras de habitarmos nesse mundo. Assumindo esse princípio fabulatório, inventivo e singular, essas composições desenrolaram-se com o tempo a partir de uma multiplicidade de tecnologias sejam elas culturais, sociais, econômicas, mitológicas, entre tantas outras. Sendo assim, as histórias que produzimos criam sentidos, realidades, mundos, verdades, valores e, igualmente, podem empobrecer existências rotulando-as.

Assim emerge a potencialidade dos contos de fadas sejam eles narrados por uma linguagem oral, escrita ou cinegrafada. Eles inventam sentidos, interrogam verdades e instigam caminhos a depender do modo como nos são apresentadas. Os seus ritmos

\footnotetext{
${ }^{18} \mathrm{O}$ filme pode ser encontrado no link a seguir: https://www.youtube.com/watch?v=tZuaN-DT0co.

${ }^{19}$ Igualmente, vale a reflexão de que os contos de fadas modernos em sua grande maioria continuam propondo que essa narrativa seja classificada como feminina e não masculina. Muitas vezes para os meninos são fabricados filmes com personagens de super-herói.
} 
movimentam fluxos que podem ser usados para investir na multiplicidade das existências ou no coroamento do uno. Podendo, portanto, conectar distintos ritmos de vidas ou aniquilar as diferenças.

No que se refere à cena narrada nessas linhas, salientamos que os usos do cinema pensados e articulados entre as professoras (a responsável pelo projeto "Cinema e Educação" e a seguidora da religião Evangélica) possibilitaram a Adílio uma narrativa que o atravessou de um modo inimaginável. Entendemos que a professora orientadora do projeto "Cinema e Educação" não via o enredo desse conto de fada como uma produção que poderia movimentar existências de vida. Já a professora evangélica envolve com esse filme, pois acredita que os papéis de filhas, mãe, relacionamentos afetivos enunciados na película são bons exemplos de comportamentos. Uma vez que, conforme as suas conversas a mesma anuncia que em sua vida (cotidiana, religiosa, profissional, etc.) confia que essas histórias transmitem bons ensinamentos para as crianças. Como, por exemplo, a existência do modo correto de se comportar das meninas e dos meninos; a crença nas boas ações para garantir um futuro de sucesso, feliz e linear; a classificação de diferentes personagens para as crianças, princesas para meninas e príncipes para meninos; como outras características, docilidade para meninas e coragem para meninos, etc.

Contudo, as duas professoras, mesmo que inconscientemente, tentam delimitar o que as crianças podem ou não assistir, pensar, afetar junto com as suas escolhas de exibir ou não histórias de contos de fadas. A prática escolar dessas docentes está atravessada por outros saberes, que são alinhavados quando colocam um currículo em movimento, levando-as a aniquilarem outras possibilidades de atravessamentos junto, por exemplo, com Adílio, que se afeta e se vê ao mesmo tempo silenciado por um contexto que dizem não pertencer ao mesmo. Ou seja, por meio de fabulações cotidianas e categorizações que as mesmas sustentam, tentam impossibilitar que sensações não planejadas emerjam.

Entretanto, Larrosa (2002) considerou que algo sempre escapa das nossas vontades e dos nossos planejamentos. Fato que também interpela os desejos das duas professoras junto com os filmes exibidos, pois Adílio não percebe o conto de fada como anunciado pela professora evangélica (que Cinderela seria uma princesa para meninas) e ao mesmo tempo, questiona a professora responsável pelo projeto sobre o porquê do filme Cinderela, que ele tanto gostou, não ter entrado no Oscar... Essa criança inaugura um inédito para as professoras, mesmo tramado a uma igreja consumida pelos pais, o 
que entendemos e produzimos junto ao mundo feminino e masculino.

A emergência e urgência do inédito causado pelas indagações de Adílio são provocativas para as produções das duas professoras. Afinal ambas são atravessadas por outros registros de histórias que fazem-nas ou não a vincular o uso do filme. A potencialidade do questionamento de Adílio vem na desconstrução das posturas e verdades que acionamos quando nos encontramos com o outro. Vivenciar a escola é ir ao encontro do inédito e do imprevisto, e a partir dele compor nossos espaços de feminilidades e masculinidades.

Portanto, os delineamentos aqui traçados transportam-nos a caminhar pelos cotidianos escolares experienciando-os e degustando-os. Experienciar e degustar que pode nos levar a conexões com distintos modos de agir, pensar, sorrir, silenciar e outros sentimentos, uma vez que, “[...] nas degustações, sentimos cheiro, textura, paladar, temperatura, então colocamos à prova aquilo que ainda não se conclui, ainda não é. Aquilo que está se fazendo, aquilo que poderá vir a ser.” (LEITE, 2011, p. 20).

Recebido em: 28-02-2019

Aceito em: 12-03-2019

\section{Referências}

BASTOS, G. M. A importância dos contos de fadas na educação infantil. Trabalho de Conclusão de Curso (graduação em Pedagogia) - Universidade de Brasília, 2015. Disponível em: http://bdm.unb.br/bitstream/10483/12925/1/2015_GabrieleMirandaBastos.pdf . Acesso em: 28 fev. de 2019.

BREDER, F. C. Feminismo e príncipes encantados: a representação feminina nos filmes de princesa da Disney. Monografia (Graduação em Comunicação Social/ Jornalismo) - Universidade Federal do Rio de Janeiro - UFRJ, Escola de Comunicação - ECO, 2013. Disponível: https://iteraturaexpandida.files.wordpress.com/2011/09/feminismo-e-prc3adncipesencantados-a-representac3a7c3a3o-feminina-nos-filmes-de-princesa-da-disney.pdf. Acesso em: 28/02/2019

COELHO, N. N. Literatura infantil: teoria, análise, didática. 1 ed. São Paulo: Moderna, 2000.

DELEUZE, Gilles. O ministério de Ariana. Lisboa: Veja, 1996.

HUSTON, N. A espécie fabuladora. Porto Alegre: L\&PM, 2010.

LARROSA, Jorge. Notas sobre a experiência e o saber de experiência. Revista Brasileira de Educação. online, n. 19, p. 20-28, 2002. 
LATOUR, Bruno. Reflexão Sobre o Culto Moderno aos Deuses Fe(i)tiches. Trad. Sandra Moreira. Bauru: EDUSC, 2002.

LEITE, C. D. P. Infância, Experiência e Tempo. São Paulo: Cultura Acadêmica, 2011 .

LOPEZ, Maximiliano. Filmar a Escola: teoria da escola. In: Larrosa Jorge (Org.). Elogio da Escola. 1. ed. Belo Horizonte: Autêntica, 2017, v. 1, p. 225-233.

SANTOS, S. M. O. dos. Os contos de fadas e o processo de individuação das crianças. Trabalho de Conclusão de Curso (Especialista em Arteterapia) - ISEPE, Rio de Janeiro, 2011. Disponível em:

http://www.arteterapia.org.br/v2/pdfs/oscontosdefadaseoprocessodeindividuacao.pdf. Acesso em: 10 jan. de 2019.

SIMONINI, E.; BOTELHO, C. R. P.; AMORIM, G. C. Cotidianos em devir. In: Alexandra Garcia; Inês Barbosa de Oliveira (Orgs.). Aventuras de conhecimento: utopias vivenciadas nas pesquisas em educação. 1. ed. Rio de Janeiro: DPetAlii, 2014, v. 1, p. $217-228$. 